\title{
PENGEMBANGAN MODUL “PEDULI IBU HAMIL” DI DESA SUMBEREJO BANYUPUTIH SITUBONDO
}

\author{
Dewi Andariya Ningsih \\ Program Studi D3 Kebidanan, Fakultas Ilmu Kesehatan Universitas Ibrahimy \\ Jl. KHR. AS Syamsul Arifin Banyuputih - Situbondo - Jawatimur - Indonesia \\ E-mail : dewiandariyaningsih@ibrahimy.ac.id
}

\section{Kata Kunci:}

Kata kunci satu, kata kunci dua, kata kunci tiga, dst (bahasa Indonesia, 3-5 kata kunci)

Keywords:

pregnant women, module

\section{Info Artikel}

Tanggal dikirim: 29-12-2019

Tanggal direvisi: $4-1-2020$

Tanggal diterima: 23-1-2020

DOI : $10.36341 /$ jomis.v4i1.1073

Attribution-NonCommercial 4.0

International. Some rights

reserved

\begin{abstract}
ABSTRAK
Angka Kematian Ibu menjadi salah satu indikator penting dari derajat kesehatan masyarakat.. Sasaran pembangunan kesehatan yang akan dicapai pada tahun 2030 adalah meningkatnya derajat kesehatan masyarakat yang salah satunya ditunjukkan dengan indikator menurunnya kematian ibu. Mengacu pada program puskesmas Banyuputih, peneliti membuat pengembangan modul Peduli Ibu Hamil yang terdiri dari Keluarga Siaga, Sehat Jiwa Dan Mengenali Tanda Bahaya Kehamilan Sejak Dini Di Desa Sumberejo Banyuputih Situbondo yang dirangkum dalam bentuk modul. Penelitian ini menggunakan metode penelitian dan pengembangan atau lebih dikenal dengan Research and Development. Subjek penelitian yang digunakan peneliti adalah seluruh ibu hamil trimester II dan III yang memenuhi kriteria inklusi dan ekslusi dan bersedia menjadi subjek penelitian.Hasil penelitian menunjukkan bahwa mayoritas responden yakni sebesar $83,3 \%$ (25 orang) mengalami peningkatan pengetahuan dan tidak ada pengetahuan yang menurun. Setelah dilakukan penelitian terdapat pengaruh terhadap peningkatan pengetahuan ibu hamil dikarenakan banyak kelebihan dari Modul Peduli Ibu Hamil yang mampu meningkatkan pengetahuan ibu dan menambah wawasan ibu hamil seputar informasi kehamilan
\end{abstract}

\begin{abstract}
Maternal mortality is one of the important indicators of the degree of public health.. The goals of health development that will be achieved in 2030 is the increase in the degree of public health, one of which is indicated by the declining indicators of maternal mortality. Referring to the Puskesmas program Banyuputih, researchers make the development of the pregnant women module that consists of the family of standby, healthy souls and recognize the signs of early pregnancy danger in the village Sumberejo Banyuputih Situbondo which is summarized in the form of Module. This research uses research and development methods or better known as Research and Development. The research subject used by researchers is all II and III trimester pregnant mothers who meet the criteria of inclusion and exclusion and are willing to be the subject of research. The results showed that the majority of respondents amounting to $83.3 \%$ (25 people) experienced increased knowledge and no declining knowledge. After research, there is an impact on increasing the knowledge of pregnant women because of the many advantages of the pregnant women care module that can improve the knowledge of mothers and increase the insight of pregnant women around pregnancy information
\end{abstract}

\section{PENDAHULUAN}

Angka Kematian Ibu (AKI) menjadi salah satu indikator penting dari derajat kesehatan masyarakat (Kemenkes, 2012). Sasaran pembangunan kesehatan yang akan dicapai pada tahun 2030 adalah meningkatnya derajat kesehatan masyarakat yang salah satunya ditunjukkan dengan indikator menurunnya Angka Kematian Ibu (AKI). Sedangkan sasaran Rencana Pembangunan Jangka Menengah Nasional (RPJMN) tahun 2016-2019 yaitu target AKI tahun 2019 adalah 306/100.000 Kelahiran Hidup (KH) (Kemenkes 2015). Permasalahan kematian ibu dan bayi baru lahir masih menjadi kendala untuk meningkatkan derajat kesehatan suatu 
bangsa. Di Indonesia angka kematian ibu (AKI) masih cukup tinggi. Data kesehatan Indonesia 2015 menunjukkan terjadinya penurunan AKI yaitu sejumlah 305 per 100.000 kelahiran hidup, dibandingkan dengan hasil Survey Demografi Kesehatan Indonesia (SDKI) 2012 yaitu 359 per 100.000 kelahiran hidup. Penurunan AKI tersebut masih jauh dari target Sustainable Development Goals (SDGs) yakni 70 per 100.000 kelahiran hidup pada tahun 2030. Menurut [3] negara-negara berkembang ada lima penyebab utama kematian ibu,diantaranya adalah perdarahan,sepsis,hipertensi akibat kehamilan,aborsi yang tidak aman dan persalinan macet. Komplikasi penyebab kematian ibu terbanyak adalah karena perdarahan pada kehamilan 45,7\%,hipertensi selama kehamilan $14,5 \%$ dan infeksi $8 \%$. Berdasarkan Laporan Kematian Ibu dari Puskesmas se Kabupaten Situbondo tahun 2017 jumlah kematian ibu adalah 10 kasus dan AKB sebanyak 58 kasus kematian [4].

Menurut [5] Pengetahuan tentang tanda bahaya kehamilan merupakan hak yang penting untuk diketahui oleh masyarakat, khususnya ibu hamil. Hal ini penting karena jika diketahui tanda-tanda bahaya dalam kehamilan diketahui sejak dini, maka penanganannya akan lebih cepat. Berkaitan dengan hal itu,para petugas kesehatan juga terus-menerus berupaya menyebarluaskan pengenalan tanda dan bahaya pada ibu hamil [6] Saat ibu hamil memiliki pengetahuan yang lebih tentang resiko tinggi kehamilan maka kemungkinan besar ibu akan berpikir untuk menentukan sikap dan berprilaku untuk mencegah,menghindari atau mengatasi masalah resiko kehamilan tersebut. Dan ibu memiliki kesadaran untuk melakukan kunjungan antenatal untuk memeriksakan kehamilannya, sehingga apabila terjadi resiko pada masa kehamilan tersebut dapat ditangani secara dini dan tepat pada tenaga kesehatan. Tanda-tanda bahaya kehamilan adalah tandatanda yang mengindikasikan adanya bahaya yang dapat terjadi selama kehamilan atau priode antenatal,yang apabila tidak dilaporkan atau ridak terdeteksi bisa menyebabkan kematian ibu. Tanda-tanda bahaya selama priode antenatal seperti perdarahan pervaginam, sakit kepala yang hebat dan menetap,perubahan visual secara tiba-tiba (pemandangan kabur, rabun senja), nyeri abdomen yang hebat, bengkak pada muka atau tangan, bayi kurang bergerak seperti biasa, ketuban pecah sebelum waktunya. Pengetahuan dan persiapan uang harus dilakukan ibu hamil yaitu mengenali tandatanda bahaya dan melaksanakan persiapan menghadapi komplikasi [7].

Dalam rencana strategis kementerian Kesehatan 2015-2019 yang menegaskan Program Indonesia sehat melalui Pendekatan Keluarga (PIS-PK) adalah program yang mendukung Gerakan Masyarakat Hidup Sehat (GERMAS) Puskesmas Banyuputih menindaklanjuti program tersebut membuat Program Inovasi Ingin Kesehatan Anda Terjaga Harus Bisa (SIKAT HABIS) [8]. Mengacu pada program tersebut kemudian peneliti membuat pengembangan modul Peduli Ibu Hamil yang terdiri dari Keluarga Siaga, Sehat Jiwa Dan Mengenali Tanda Bahaya Kehamilan Sejak Dini Di Desa Sumberejo Banyuputih Situbondo yang dirangkum dalam bentuk modul. Modul merupakan salah satu bahan ajar cetak yang memiliki beberapa kelebihan dibandingkan dengan bahan ajar cetak lainnya [9]. Pada modul penelitian ini memiliki strategi pendekatan yang inovatif dengan melibatkan keluarga sebagai sasaran pembangunan kesehatan. Penyusunan modul ini merupakan upaya promotif dan preventif untuk meningkatkan kesehatan ibu dan dan anak ole bidan. Proporsi tenaga pemeriksa 
kehamilan di Indonesia $85 \%$ adalah bidan [10].

Kehamilan adalah saat-saat yang paling dinantikan oleh para kaum ibu. Oleh karena itu pemeriksaan selama kehamilan umumnya oleh bidan sangat penting dilakukan. Selain untuk memastikan bayi berkembang sehat dan normal, juga untuk mengetahui kelainan yang mungkin terjadi. Semakin awal kelainan didiagnosis, semakin mudah mengatasinya [11]. Continuity of care yang dilakukan oleh bidan memberikan pelayanan yang sama terhadap perempuan di semua kategori (tergolong kategori tinggi maupun yang rendah) serta berdasarkan evidence based perempuan yang melahirkan di bidan memiliki intervensi intrapartum yang lebih sedikit termasuk operasi saesar [12]. Kendala yang dihadapi dalam pelaksanaan pelayanan kesehatan ibu hamil tidak hanya dari sisi akses. Kualitas pelayanan yang diberikan juga harus ditingkatkan, di antaranya pemenuhan semua komponen pelayanan kesehatan ibu hamil harus diberikan saat kunjungan [13] Modul penelitian ini dapat digunakan sebagai pedoman bagi setiap anggota keluarga yang memiliki ibu hamil dalam memberikan dukungan penuh kepada ibu hamil sehingga masa kehamilan dapat dipersiapkan dengan maksimal untuk menciptakan generasi yang sehat secara fisik maupun psikisnya. Hal ini menjadi sangat penting untuk ditindaklanjuti agar berkurangnya dampak dari hal-hal yang telah disebutkan di atas. Dari latar belakang tersebut peneliti tertarik untuk melakukan penelitian yang berjudul "Pengembangan Modul Peduli Ibu Hamil Di Desa Sumberejo Banyuputih Situbondo". Berdasarkan latar belakang di atas, maka penulis membuat rumusan masalah yang terdiri dari Apakah pengembangan modul Peduli Ibu Hamil dapat meningkatkan pengetahuan ibu hamil Di Desa Sumberejo
Banyuputih Situbondo ? dan Apakah modul Peduli Ibu Hamil layak digunakan untuk ibu hamil dalam upaya preventif tanda bahaya kehamilan Di Desa Sumberejo Banyuputih Situbondo?

\section{TINJAUAN PUSTAKA}

Menurut jurnal yang berjudul Preconception planning to reduce the risk of perinatal depression and anxiety disorders, wanita lebih mudah mengalami kecemasan dan stress dibandingkan dengan pria, dan kecemasan ini dialami oleh lebih dari $50 \%$ wanita didunia. Wanita yang pernah mengalami kecemasan / stres/ depresi cenderung akan berulang, terutama pada saat wanita tersebut hamil dan pada masa postpartumnya. Gangguan kecemasan adalah sekelompok penyakit mental yang menyebabkan orang merasa terlalu takut, tertekan, atau gelisah dalam situasi di mana kebanyakan orang lain tidak akan mengalami perasaan yang sama. Gangguan kecemasan adalah penyakit mental yang paling umum di Amerika: mereka mempengaruhi sekitar 20 persen dari populasi pada waktu tertentu. Wanita yang memiliki gangguan depresi dan kecemasan berada pada risiko tinggi untuk kekambuhan atau eksaserbasi gejala kejiwaan mereka selama kehamilan dan / atau setelah melahirkan. Risiko ini dapat dikurangi dengan menerapkan langkah-langkah pencegahan sebelum konsepsi. Sebuah penilaian klinis prasangka sistematis dapat mengidentifikasi faktor-faktor yang dapat menyebabkan risiko wanita untuk mengembangkan depresi perinatal dan / atau kecemasan. Masingmasing faktor ini bisa menerima intervensi yang bisa memperkuat ketahanan wanita dan mengurangi kemungkinan dia terkena komplikasi psikiatri perinatal. Faktor risiko tertentu yang dapat dipengaruhi oleh intervensi pencegahan, dan menggambarkan komponen perencanaan prasangka efektif bagi wanita dengan gangguan depresi dan kecemasan [14] Keluarga siaga perlu mengetahui tentang Program Perencana Pesalinan dengan Pencegahan Komplikasi (P4K). Program P4K ini bertujuan untuk mngaktifkan peran 
keluarga dan masyarakat dalam persiapan persalinan yang aman untuk mengurangi jumlah kesakitan dan kematian ibu dan anak. Kegiatan dalam program tersebut dijelaskan seperti berikut ini. Peran keluarga (khususnya suami) dalam perencanan persalinan aman: Menentukan tempat dan penolong persalinan, Memberitahukan keluhan kehamilan istri kepada kepada petugas kesehata, Mengetahui hal-hal yang perlu dipersiapkan oleh istri menjelang persalinan, Mengetahui tanda tanda istri yang akan melahirkan seperti keluarnya cairan bening dari jalan lahir dan mulas di daerah perut, Menyiapkan biaya melahirkan, Mendukung upaya rujukan setelah persalinan bila diperlukan, Menyiapkan calon pendonor darah untuk persiapan jika terjadi gawat darurat pada ibu. Wanita akan mengalami sejumlah perubahan fisik maupun emosi oleh karena itu sangat dibutuhkan dukungan dari lingkungan sosialnya. Sumber dukungan sosial bisa berasal dari keluarga, sahabat, teman, rekan kerja, tetangga, dan tenaga kesehatan agar dapat menyesuaikan diri dengan kehamilanya. Keluarga (suami, ibu kandung, ibu mertua) sebagai bagian terdekat dalam kehidupan ibu sangat dibutuhkan untuk mendukung dan membantu ibu menjalani masa kehamilanya sampai melahirkan nanti. Pada prinsipnya kebutuhan dasar manusia ada 3 yaitu cukup nutrisi, cukup istirahat dan cukup apresiasi.

\section{METODE}

Penelitian ini menggunakan metode penelitian dan pengembangan atau lebih dikenal dengan Research and Development. Subjek penelitian yang digunakan peneliti adalah seluruh ibu hamil trimester II dan III yang memenuhi kriteria inklusi dan ekslusi dan bersedia menjadi subjek penelitian. Teknik pengambilan sampel dilakukan dengan cara quota sampling sejumlah 30 orang. Pada penelitian ini menggunakan metode penelitian true exsperiment dengan teknik pre-post test with one group design. Subjek yang telah memenuhi kriteria dipilih sebagai sampel penelitian. Subjek akan diambil data pengetahuan tentang keluarga Siaga, Sehat
Jiwa ibu hamil dan tanda bahaya kehamilan terlebih dulu sebagai data awal. Kemudian subjek diberi modul "Peduli Ibu Hamil" dan dilakukan uji coba modul pada responden dan bidan. Setelah mendapat masukan, usulan dan saran perbaikan maka modul diperbaiki sesuai masukan responden. Setelah modul direvisi dan telah sesuai maka diberikan kepada responden untuk dipelajari dan dipahami serta diskusi jika terdapat hal yang tidak dimengerti. Setelah 1 minggu maka dilakukan post test. Data yang telah didapatkan akan dianalisa dengan menggunakan uji Paired samples test. Untuk mengevaluasi penerapan modul peduli ibu hamil setiap hari menggunakan instrument lembar observasi penggunaan modul. Lembar observasi ini diisi oleh keluarga ibu hamil sendiri untuk menandai bahwa ibu hamil telah melakukan penerapan modul sebagai panduan preventif faktor resiko. Observasi yang dilakukan oleh enumerator merupakan observasi tidak langsung. Observer yang dipilih peneliti adalah kader dengan kriteria bisa membaca dan menulis, kader yang aktif dalam kegiatan sebagai kader, tidak memiliki konflik dengan ibu hamil yang bersangkutan dan bersedia menjadi observer yang telah menandatangani informed concent. Sebelumnya observer diberikan penjelasan tentang cara mengisi lembar observasi untuk mengantisipasi adanya pertanyaan dari subyek yang kurang dimengerti dan akan dibahas tuntas.

\section{HASIL DAN PEMBAHASAN}

Karakteristik Ibu Hamil Desa Sumberejo Banyuputih Situbondo Tahun 2019

\begin{tabular}{ccc}
\hline Data Umum & $\begin{array}{c}\text { Frekuensi } \\
\text { (orang) }\end{array}$ & $\begin{array}{c}\text { Persentase } \\
(\boldsymbol{\%})\end{array}$ \\
\hline Umur (Th) & & \\
\hline $17-25$ & 22 & 73,3 \\
\hline $26-35$ & 8 & 26,7 \\
\hline Total & $\mathbf{3 0}$ & $\mathbf{1 0 0}$ \\
\hline Pendidikan & & \\
\hline SD & 2 & 6,7 \\
\hline SMP & 4 & 13,3 \\
\hline SMA & 15 & 50 \\
\hline PT & 9 & 30 \\
\hline
\end{tabular}


JOMIS (Journal of Midwifery Science)

Vol 4. No.1, Januari 2020

\begin{tabular}{ccc}
\hline Total & $\mathbf{3 0}$ & $\mathbf{1 0 0}$ \\
\hline Pekerjaan & & \\
\hline PNS & 3 & 10 \\
\hline SWASTA & 7 & 23,3 \\
\hline IRT & 20 & 66,7 \\
\hline Total & $\mathbf{3 0}$ & $\mathbf{1 0 0}$ \\
\hline Trimester & & \\
\hline II & 13 & 43,3 \\
\hline III & 17 & 56,6 \\
\hline Total & $\mathbf{3 0}$ & $\mathbf{1 0 0}$ \\
\hline
\end{tabular}

Berdasarkan tabel diatas karakteristik

ibu hamil berdasarkan umur, persentase tertinggi yaitu pada kategori umur antara 1725 tahun sebanyak $73,3 \%$ (22 orang) dan persentase terendah pada kategori umur antara 26-35 tahun sebanyak 26,7\% (8 orang). Distribusi berdasarkan pendidikan terakhir ibu diklasifikasikan menjadi SD, SMP, SMA dan PT. Data menunjukkan bahwa persentase tertinggi responden memiliki pendidikan terakhir pada tingkat SMA sebanyak 50\% (15 orang) dan persentase terendah adalah SD sebanyak $6,7 \% \quad$ (2 orang). Distribusi berdasarkan pekerjaan dibedakan menjadi PNS, Wiraswasta, ibu rumah tangga (IRT). Responden dengan presentase tertinggi sebesar $66,7 \%$ (20 orang) adalah IRT dan presentase terendah $10 \%$ (3 orang) adalah PNS. Distribusi berdasarkan trimester kehamilan dibedakan menjadi trimester II \& III. Mayoritas responden adalah ibu hamil trimester III sebanyak 56,6\% (17 orang).

Perubahan Pengetahuan sebelum dan sesudah pemberian Modul Peduli Ibu Hamil Pada keluarga Ibu Hamil Di Desa Sumberejo Banyuputih Situbondo

\begin{tabular}{ccc}
\hline $\begin{array}{c}\text { Pengetah } \\
\text { uan }\end{array}$ & $\begin{array}{c}\text { Frekue } \\
\text { nsi (orang) }\end{array}$ & $\begin{array}{c}\text { Persenta } \\
\text { se (\%) }\end{array}$ \\
\hline Meningka & 25 & 83,3 \\
t & 5 & 16,7 \\
Tetap & 0 & 0 \\
Menurun & & \\
\hline Total & 30 & 100 \\
\hline
\end{tabular}

P-ISSN : 2549-2543

E-ISSN : 2579-7077

Tabel diatas menunjukkan bahwa mayoritas responden yakni sebesar 83,3\% (25 orang) mengalami peningkatan pengetahuan dan tidak ada pengetahuan yang menurun

\section{Pengembangan modul Peduli Ibu Hamil Di Desa Sumberejo Banyuputih Situbondo}

Modul Peduli Ibu Hamil dirancang sangat menarik dengan informasi lengkap mengenai informasi dengan cara pendekatan kesehatan keluarga serta gambar yang disajikan dalam bentuk gambar di modul sehingga mudah dipahami dan mampu meningkatkan pengetahuan ibu dalam mengenali tanda bahaya kehamilan. Berdasarkan uji statistik didapatkan bahwa terdapat peningkatan skor pengetahuan, studi menyebutkan bahwa pengetahuan Ibu dipengaruhi oleh usia dan pendidikan Ibu. Pada penelitian ini sebagian besar Ibu pada berusia 17-25 tahun dan pendidikan SMA (Sekolah Menengah Atas).

Hasil dari beberapa penelitian tentang modul menyebutkan bahwa modul efektif meningkatkan pengetahuan pengguna modul. Hal ini dapat dilihat dari hasil penelitian bahwa ada pengaruh penggunaan modul menarche terhadap pengetahuan tentang menarche (Jumiyati, Nugrahaeni and Margawati, 2014; Mendri et al., 2014). Peningkatan pengetahuan ibu hamil dapat meningkatkan kepatuhan mengkonsumsi TTD (Iswanto, Ichsan and Ermawati, 2012; Nora, 2012; Sulistyanti, 2015). Begitupula dengan peningkatan pengetahuan suami ibu hamil dapat meningkatkan keikutsertaan suami dalam mendampingi ibu hamil mencegah anemia pada kehamilan (Aminin and Dewi, 2017). Keikutsertaan suami ibu hamil diharapkan meningkatkan kepatuhan ibu hamil mengkonsumsi TTD. Modul merupakan seperangkat bahan ajar yang dikemas secara utuh dan sistematis, didalamnya memuat seperangkat pengalaman belajar yang terencana dan didesain untuk mencapai tujuan belajar yang spesifik (Daryanto, 2013). Modul dapat digunakan dan dipelajari setiap waktu, sehingga tidak terikat oleh waktu. Sedangkan jika dibandingkan dengan leaflet, modul dapat 
memberikan informasi yang lebih lengkap dan jelas (Mendri et al., 2014).

\section{Validasi Modul Peduli Ibu Hamil Di Desa Sumberejo Banyuputih Situbondo}

Pemilihan media modul sebagai media penelitian dikarenakan Modul memiliki ukuran yang relatif baik, sehingga akan memudahkan klien untuk memahami meteri yang menuntut klien mengenal cara mengantisipasi tanda bahaya pada ibu hamil. Selain itu salah satu fungsi Modul menurut Sulistyani, dkk.2013 yaitu fungsi atensi, bahwa media Modul yang dicetak dengan kemasan baik dan full colour dapat menarik dan perhatian pembaca untuk berkonsentrasi pada isi materi yang tertulis didalamnya.

Sebelum dapat diaplikasikan untuk media penelitian, Modul ini divalidasi terlebih dahulu. Validasi dilakukan oleh 5 orang validator, yaitu tiga orang dosen Prodi DIII Kebidanan dan dua orang bidan. Hal ini dimaksudkan agar bidan dapat mengenalkan kepada klien mengenai cara pendekatan kesehatan keluarga yang ada di daerah Sumberejo. Selain itu hubungan bidan dan klien yang berkualitas merupakan dasar pelayanan kebidanan. Beberapa studi menunjukkan bahwa hubungan saling percaya antara perempuan dan bidan mencakup aspek emosional yang dapat meningkatkan kepuasan klien dalam layanan kebidanan [15]

Terdapat tiga aspek dalam validasi media buku saku, yakni format, isi, dan Bahasa [16]. Aspek format mendapatkan nilai total 3,7 (kategori valid). Aspek format terbagi menjadi 4 kriteria. Kriteria pertama yaitu kemudahan membawa Modul yang memperoleh nilai rata-rata 3,6. Salah satu validator memberikan komentar bahwa setiap klien berbeda-beda dan belum tentu Modul yang dibuat dapat dimasukan ke dalam tas tiap Ibu Hamil. Kriteria kedua adalah kesesuaian huruf tulisan (font) pada media Modul dengan nilai rata-rata 3,6. Modul ini disusun menggunakan huruf Times New Roman 11. Ukuran huruf sudah sesuai dan dapat dibaca dengan jelas, namun demikian salah satu validator yaitu bidan wilayah Sumberejo mengatakan bahwa jenis huruf yang digunakan sebaiknya di buat sedikit bervariasi agar megurangi kejenuhan Ibu Hamil saat membaca. Penggunaan huruf Times New Roman 11 ini dimaksudkan untuk efisiensi halaman buku, karena jika menggunakan ukuran huruf yang terlalu besar akan membuat halaman buku lebih banyak dan buku akan terlihat tebal. Sulistyani dkk. (2013) menyatakan bahwa Modul dicetak dengan ukuran yang kecil agar lebih efisien, praktis, dan mudah dalam menggunakannya. Modul yang tebal tentu akan mengurangi minat Ibu Hamil untuk membacanya. Kriteria ketiga yaitu kemenarikan gambar pada buku saku. Dari hasil validasi diperoleh nilai rata-rata 3,8. Dalam Modul ini gambar yang disajikan meliputi gambar sesuai kajian per masing masing tema. Gambar-gambar yang disajikan dalam Modul ini merupakan daya tarik utama, ini di dukung oleh pernyataan Arsyad (2011) yang mengatakan bahwa ukuran yang relatif kecil dan memuat berbagai gambar-gambar berwarna tentu merupakan keunggulan dan daya tarik tersendiri untuk modul. Selain itu salah satu fungsi Modul menurut Sulistyani, dkk. (2013) adalah fungsi kognitif dimana penulisan rumus dan gambar pada Modul dapat memperjelas materi yang terkandung di dalam buku sehingga dapat memperlancar pencapaian tujuan pembelajaran. Tiga orang validator mengatakan bahwa gambar yang ditampilkan sudah menarik, hanya saja masih ada beberapa gambar yang kurang jelas dan itu dikarenakan ukuran gambar yang besar, sehingga fokus gambar kurang baik. Kriteria keempat yaitu kemenarikan desain cover buku saku. Berdasarkan hasil validasi diperoleh nilai rata-rata 3,8. Hal ini menunjukkan bahwa desain cover sudah menarik. Desain cover dibuat dengan menampilkan gambar-gambar sesuai dengan bahasan. Arsyad (2009) mengatakan bahwa warna dapat mempertinggi tingkat realisme objek. Sehingga dari gambargambar yang disajikan pada cover dapat menarik minat pembaca khususnya Ibu Hamil. Selain itu juga Azalea (2015) mengatakan bahwa warna merupakan unsur yang sangat tajam untuk menyentuh kepekaan penglihatan sehingga mampu merangsang munculnya rasa haru, sedih, gembira, mood, 
atau semangat dan lain-lain. Kekurangan dari desain cover buku ini yaitu terdapat beberapa gambar yang sedikit buram yang di sebabkan oleh pengambilan gambar yang kurang baik, terutama karena kurangnya pencahayaan dan fokus kamera yang kurang. Aspek isi dari hasil analisis validasi mendapat nilai rata-rata tiap aspek 3,8 .

Ada tiga kriteria untuk aspek isi. Kriteria pertama yaitu kemudahan mengingat submateri peduli ibu hamil dengan nilai ratarata tiap kriteria sebesar 3,8. Materi pada Modul ini disajikan dengan ringkas, singkat namun jelas dan mudah dipahami. Hal ini berkaitan dengan fungsi psikomotoris modul yaitu penulisan materi modul yang singkat dan jelas dapat mempermudah klien untuk memahaminya (Sulistyani, dkk., 2013). Menurut komentar salah satu informan bahwa materi pada Modul perlu ditambah lagi agar informasi yang disajikan lebih luas. Kriteria kedua yaitu media Modul dapat membantu klien dalam memahami submateri BBLR nilai rata-ratanya adalah 3,9. Dari rata-rata validasi tersebut artinya untuk kriteria ini sudah sangat baik, Modul ini menyajikan informasi mengenai kesehatan ibu hamil. Kriteria ketiga yaitu kelengkapan penyajian informasi kesehatan ibu hamil, nilai rata-ratanya adalah 4. Informasi yang disajikan sudah cukup lengkap, dimana informasi yang disajikan meliputi keluarga siaga, sehat jiwa dan mengenali tanda bahaya sejak dini

Aspek yang ketiga adalah aspek bahasa, nilai rata-ratanya 3,8. Aspek bahasa juga terdiri dari tiga kriteria. Kriteria pertama yaitu kejelasan susunan kalimat dalam media Modul dengan nilai rata-rata 3,8. Dari nilai rata-rata ini terlihat bahwa kalimat dalam Modul sudah jelas, sistematis dan tidak menimbulkan penafsiran ganda. Kriteria kedua yaitu penggunaan bahasa dalam media Modul sesuai dengan kaidah EYD, nilai rata-ratanya 3,6 dan ini menunjukan bahwa bahasa yang digunakan dalam Modul ini minimal sudah terdiri dari subjek dan predikat serta baik dan benar sesuai EYD, hanya saja berdasarkan komentar validator masih ada beberapa bahasa yang kurang sesuai dengan EYD. Kriteria ketiga yaitu keefektifan kalimat yang digunakan pada Modul dengan nilai rata-rata 3,8. Salah satu informan mengatakan bahwa masih ada beberapa kalimat yang kurang efektif karena bukan merupakan bahasa formal sehari-hari sehingga akan membuat klien menjadi bingung dan sulit mengerti arti dari kata kersebut. Dari hasil pengujian validasi media Modul didapatkan nilai rata-rata total validasi adalah 3,8. Sehingga Modul Peduli Ibu Hamil sebagai upaya pendekatan kesehatan keluarga Pada ibu hamil di desa sumberejo Banyuputih situbondo ini dapat dikatakan layak untuk digunakan sebagai media informasi untuk ibu ibu hamil untuk kehamilan yang sehat dan bahagia.

\section{KESIMPULAN}

Berdasarkan hasil penelitian yang telah dilakukan dengan judul pengembangan modul Peduli Ibu Hamil sebagai upaya pendekatan kesehatan keluarga Pada ibu hamil di desa sumberejo Banyuputih situbondo didapatkan jumlah responden sebanyak 30 orang disimpulkan sebagai berikut karakteristik ibu hamil tertinggi adalah umur 17 - 25 tahun yakni sebanyak 73,3\% (22 orang).

Setelah dilakukan penelitian terdapat pengaruh terhadap peningkatan pengetahuan ibu hamil dikarenakan banyak kelebihan dari Modul Peduli Ibu Hamil yang mampu meningkatkan pengetahuan ibu dan menambah wawasan ibu hamil seputar informasi kehamilan.

\section{DAFTAR PUSTAKA}
[1] R. Kemenkes, "Profil Kesehatan Indonesia 2012," 2012.
[2] Kemenkes, "Rencana Strategis
Kementerian Kesehatan Tahun 2015- 2019," Jakarta, 2015. 
[3] V. Helen and G. C. Kriebs Jamn M, Buku Ajar Asuhan Kebidanan (4th ed). Jakarta: Penerbit Buku Kedokteran EGC, 2017.

[4] "Profil kesehatan Kabupaten Situbondo tahun 2017."

[5] A. Mieke and M. I. Kartasurya, "Analisis Implementasi Program Pelayanan Antenatal Terpadu pada Ibu Hamil dengan Malaria di Puskesmas Tobelo Kabupaten Halmahera Utara Provinsi Maluku Utara Analysis on the Implementation of Integrated Antenatal Care Program to Pregnant Women with Malaria," vol. 01, no. 02, pp. 123-129, 2013.

[6] Hidayatun Mukaromah, "Analisis Faktor Ibu Hamil terhadap Kunjungan Antenatal Care di puskesmas Siwalankerto Kecamatan Wonocolo Kota Surabaya," J. Promkes, vol. 2, pp. 39-48, 2014.

[7] A. Maisura and Darmawati, "Efektivitas Penyuluhan Kesehatan Pengetahuan Tanda Bahaya Kehamilan Pada Ibu Hamil Di Puskesmas Darussalam," J. Ilm. Mhs. Fak. Keperawatan, vol. 1, no. 1, pp. 1-6, 2016.

[8] "Profil Kesehatan UPTD Puskesmas Banyuputih,” 2017.

[9] BPPK, Pedoman Penulisan Modul. Jakarta, 2009.

[10] K. Kesehatan and B. P. dan P. Kesehatan, "Hasil Utama Riskesdas 2018." 2018.

[11] Menkes, "Peraturan Menteri Kesehatan Republik Indonesia Nomor 28 Tahun 2017," 2017.

[12] D. A. Ningsih, "Continuity of Care Kebidanan," Oksitosin, vol. IV, no. 2, pp. 67-77, 2017.

[13] K. Kesehatan and R. Indonesia, "Profil Kesehatan Indonesia Tahun 2017," 2017.

[14] O. Avni-Barron, K. Hoagland, C. M. Ford, and L. J, "Preconception planning to reduce the risk of perinatal depression and anxiety disorders," $J$. Expert Rev. Obstet. Gynecol., no. 4, 2010.
[15] D. andariya Ningsih, "Partnership Dalam Pelayanan Kebidanan," Proceeding B. Simp. dan Work. Nas. Pengemb. Pendidik. dan Pelayanan Kebidanan Indones., pp. 168-172, 2015.

[16] Yamasari, "Pengembangan Media Pembelajaran Matematika Berbasis ICT yang Berkualitas," 2010. 